\title{
Heart-lung transplantation in patients with pulmonary atresia and ventricular septal defect
}

\author{
Katarzyna Januszewska, MD, PhD, Edward Malec, MD, PhD, Gerd Juchem, MD, PhD, \\ Ingo Kaczmarek, MD, PhD, Ralf Sodian, MD, PhD, Peter Uberfuhr, MD, PhD, \\ and Bruno Reichart, $\mathrm{MD}, \mathrm{PhD}$
}

Objective: Heart-lung transplantation for patients with pulmonary atresia and ventricular septal defect is challenging. The aim of the study was to present a single-center experience with heart-lung transplantation in this difficult group of patients.

\begin{abstract}
Methods: A retrospective review identified 9 patients aged 4.1 to 45.6 years (median, 25.4 years) with pulmonary atresia and ventricular septal defect who underwent heart-lung transplantation. Four $(44.4 \%)$ patients had previous heart operations: 3 of them had palliative procedures (systemic-to-pulmonary shunts), and 1 had multistage correction. A standard transplantation method was used, with the exception of 1 patient with heterotaxy syndrome who underwent a modified operation. Major aortopulmonary collateral arteries were controlled by using various techniques.
\end{abstract}

Results: Follow-up ranged between 2 days and 12.6 years (median, 1.2 years). The hospital mortality rate was $22.2 \%(n=2)$. In the late postoperative period, 3 patients died. The survival curve was similar to that of patients with other diagnoses undergoing heart-lung transplantation. The median length of intensive care unit stay was 58 days (range, 22-82 days), and the median length of hospital stay was 83 days (range, 35-136 days). The most common early complication was bleeding requiring re-exploration. In all cases the bleeding was proved to be from collateral vessels.

Conclusions: Heart-lung transplantation in patients with pulmonary atresia and ventricular septal defect requires carefully planned and meticulously performed surgical intervention. This management should be taken into consideration as a future option if the specific anatomy is uncorrectable in early childhood, and the palliative procedures should be avoided.

The most common indication for heart-lung transplantation (HLTx) today is congenital heart disease. ${ }^{1}$ Although combined heart and lung transplantation is a conceptually simple procedure, requiring only 3 relatively easy anastomoses, for some congenital heart defects, this operation might be challenging. Patients with pulmonary atresia with ventricular septal defect (PA+VSD; tetralogy of Fallot with pulmonary atresia) present technical difficulties because of numerous collateral vessels, adhesions caused by previous operations, and often coexistence of unusual anatomy and are usually in worse condition than other transplant recipients (usually with renal and hepatic dysfunction). These patients are challenging at every stage of clinical management.

The aim of this retrospective study was to present a singlecenter experience with HLTx in patients with PA+VSD to analyze the methods used in management and the problems

From the Department of Cardiac Surgery, Klinikum Grosshadern, Ludwig Maximilians University, Munich, Germany.

Received for publication Sept 12, 2008; revisions received Nov 18, 2008; accepted for publication Dec 25, 2008; available ahead of print June 24, 2009.

Address for reprints: Katarzyna Januszewska, MD, PhD, Department of Cardiac Surgery, Klinikum Grosshadern, Marchioninistr. 15, 81377 Munich, Germany (E-mail: mijanusz@cyf-kr.edu.pl).

J Thorac Cardiovasc Surg 2009;138:738-43

$0022-5223 / \$ 36.00$

Copyright (c) 2009 by The American Association for Thoracic Surgery doi:10.1016/j.jtcvs.2008.12.054 encountered. To our knowledge, this is the first analysis dedicated to this very difficult homologous group of patients.

\section{MATERIALS AND METHODS}

Between February 1983 and March 2008, 73 patients underwent HLTx at the Department of Cardiac Surgery, Klinikum Grosshadern, Ludwig Maximilians University, Munich, Germany. A retrospective review identified 9 patients, $4(44.4 \%)$ female and $5(55.6 \%)$ male, who underwent HLTx for PA+VSD.

Patient age at the time of transplantation ranged from 4.1 to 45.6 years (mean \pm standard deviation, $27.4 \pm 15.3$ years; median, 25.4 years). All the children $(n=2)$ and $86 \%$ of the adult patients $(n=6)$ were underweight (adult body mass index: range, $17.0-29.9 \mathrm{~kg} / \mathrm{m}^{2}$; median, $20.1 \mathrm{~kg} / \mathrm{m}^{2}$ ). All patients were symptomatic because of effort intolerance and dyspnea of various degrees and had New York Heart Association class III to IV symptoms. Cyanosis was evident, and clubbing was noted. The median arterial oxygen saturation was $73.0 \%$ (range, $60 \%-80 \%$ ), and the median hemoglobin value was $20.8 \mathrm{~g} / \mathrm{dL}$ (range, $14.5-24.0 \mathrm{~g} / \mathrm{dL}$ ). Six $(66.7 \%$ ) patients required continuous supplemental oxygen, and in 3 of them, regular phlebotomies were performed for polycythemia to decrease the hematocrit value. In $4(44.4 \%)$ patients multiple supraventricular and ventricular arrhythmias occurred, and 2 of them survived episodes of ventricular fibrillation, from which they were resuscitated without sequel. Four $(44.4 \%)$ patients had chronic renal insufficiency in a compensatory phase, $2(22.2 \%)$ had congenital kidney malformation, 3 $(33.3 \%)$ had hepatic dysfunction caused by prolonged congestion, 1 survived endocarditis, and 1 underwent phlebothrombosis of the left popliteal vein. Because of progressive disability, poor life expectancy, and absence of alternative therapeutic options, the patients were put on the HLTx waiting list.

All patients were subjected to cardiac catheterization and angiography, the latter including multiple injections into the thoracic aorta and selective injections into the large collateral arteries. All patients had major aortopulmonary 


\section{Abbreviations and Acronyms \\ $\mathrm{CMV}=$ cytomegalovirus \\ $\mathrm{CPB}=$ cardiopulmonary bypass \\ HLTX = heart-lung transplantation \\ MAPCA $=$ major aortopulmonary collateral artery \\ $\mathrm{PA}+\mathrm{VSD}=$ pulmonary atresia with ventricular septal defect}

collateral arteries (MAPCAs; Figure 1). Four (44.4\%) patients had previous heart operations: 3 of them underwent palliative procedures (systemic-topulmonary shunts), and 1 patient (no. 5) had multistage correction (right ventricular outflow tract reconstruction with atrial and ventricular septal defect closure and MAPCA ligation). One patient (no. 3) underwent dilatation of a stenotic MAPCA with stent implantation. Details of previous procedures, as well as preoperative characteristics, are presented in Table 1.

For donor cardiac preservation, Bretschneider cardioplegic solution was used until 1994, when it was replaced by University of Wisconsin solution. Pulmonary procurement was performed with Euro-Collins solution until 1996, and thereafter it was replaced with Perfadex solution. A median sternotomy incision was used in all recipients with no history of previous sternotomies. In the remainder a bilateral transverse thoracotomy ("clamshell incision") was done. Collateral vessels, as many as possible, were identified before institution of cardiopulmonary bypass (CPB) and ligated or oversewn immediately after starting CPB. In 5 patients it was necessary to institute profound hypothermia and decrease the perfusion rate to control the bleeding from the collateral arteries. Extensive and large collateral arteries were controlled after clamping of the entire hilum. MAPCAs arising from the descending aorta were dissected by means of incision of the posterior pericardium. Once the hemostasis was achieved, the donor heart-lung bloc was implanted according to the technique described by Reitz and associates. ${ }^{2}$

In patient 9 , who had heterotaxy syndrome, dextrocardia, situs inversus atrialis, single ventricle (unbalanced atrioventricular canal with hypoplastic left ventricle), and agenesis of the right superior vena cava with persistence of the left superior vena cava, a modified implantation technique was used. The inferior and superior venae cavae drained to the left-sided recipient atrium (atrial inversion). After removal of the recipient heart, the remnants of the left-sided right atrium were sewn together and anastomosed with the donor right atrium, with the rotation of the donor heart in a clockwise direction in the long axis of about $60^{\circ}$.

Immunosuppressive treatment consisted of a combination of cyclosporin A, azathioprine, and steroids. This regimen was applied until 1995, when cyclosporine was replaced with tacrolimus. In 1997, azathioprine was replaced with mycophenolate mofetil. Methylprednisone was initiated intraoperatively with a 500-mg intravenous bolus and tapered down to $0.1 \mathrm{mg} \cdot \mathrm{kg}^{-1} \cdot \mathrm{d}^{-1}$ within 6 months. Dosing of cyclosporine A, tacrolimus, and mycophenolate mofetil was titrated to maintain a serum concentration of between 250 and $300 \mathrm{ng} / \mathrm{mL}, 10$ and $15 \mathrm{ng} / \mathrm{mL}$, and 2 and $4 \mu \mathrm{g} / \mathrm{mL}$, respectively. Azathioprine was administered in a daily dose of 0 to $2 \mathrm{mg} / \mathrm{kg}$ to maintain a white blood cell count of greater than 4000 cells $/ \mathrm{mL}$.

Antibacterial prophylaxis included imipenem for the first 48 hours after HLTx. Antifungal prophylaxis with oral nystatin and aerosolized amphotericin B was administered within the 7 first postoperative days. Cytomegalovirus (CMV) prophylaxis with ganciclovir was used in any CMV-positive recipient and in any $\mathrm{CMV}$-negative recipient receiving an allograft from a CMV-positive donor. Pneumocystis carinii prophylaxis consisted of trimethoprim-sulfamethoxazole.

During follow-up, patients were reviewed at regular intervals: once a week for the first 2 months and then gradually extended to 3-month intervals.

Statistical analysis was carried out by means of descriptive statistics and the Mann-Whitney test for continuous variables. Patient survival was esti-
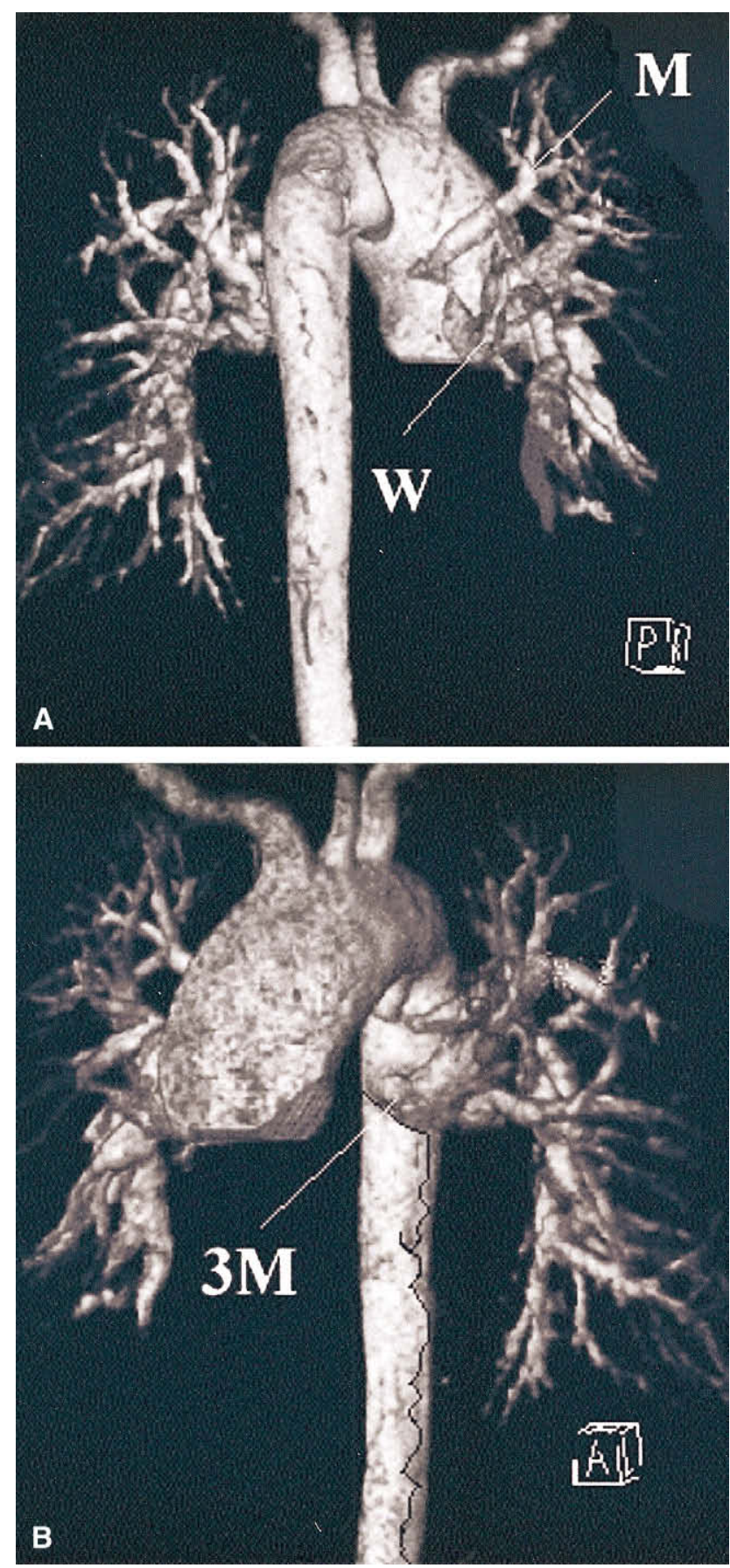

FIGURE 1. Collateral vessels in patient 8: A, posterior aspect of the aorta showing MAPCAs $(M)$ from the aortic arch and Waterstone shunt $(W)$; B, anterior aspect of the aorta showing 3 MAPCAs $(3 M)$ from the descending aorta.

mated by using the Kaplan-Meier method. Data are presented as mean values with standard deviations or median values with ranges.

\section{RESULTS}

Donors for the recipients reported here were found within a median waiting period of 60 days (range, 38-458 days). 
TABLE 1. Clinical and morphologic characteristics of the patient population

\begin{tabular}{|c|c|c|c|c|c|c|c|c|c|c|}
\hline \multirow{2}{*}{$\begin{array}{l}\text { Patient } \\
\text { no. }\end{array}$} & \multirow{2}{*}{$\begin{array}{c}\text { Age } \\
(\mathbf{y})\end{array}$} & \multirow{2}{*}{$\begin{array}{c}\text { Weight } \\
(\mathrm{kg}) / \mathrm{BMI}\end{array}$} & \multicolumn{2}{|c|}{$\begin{array}{l}\text { Associated } \\
\text { features }\end{array}$} & \multicolumn{2}{|c|}{$\begin{array}{l}\text { Pulmonary } \\
\text { arteries }\end{array}$} & \multicolumn{2}{|c|}{ MAPCAs } & \multicolumn{2}{|c|}{$\begin{array}{l}\text { Previous operations/ } \\
\text { catheter interventions }\end{array}$} \\
\hline & & & Cardiac & Noncardiac & MPA/Confl & LPA/RPA & No. & Origin & Age & Operation/approach \\
\hline 1 & 25.4 & $51.0 / 17.0$ & $\begin{array}{l}\text { Aberrant right } \\
\text { subclavian artery }\end{array}$ & & $0 / 0$ & $0 / 0$ & 1 & AoArch & & 0 \\
\hline 2 & 8.2 & $18.0 / 10.6$ & & & $0 / 1$ & $\mathrm{H} / \mathrm{H}$ & 1 & Tr Br-ceph & $\begin{array}{l}2 \mathrm{y} \\
4 \mathrm{y}\end{array}$ & $\begin{array}{c}\text { LBTS/LTh } \\
\text { Waterstone/S }\end{array}$ \\
\hline 3 & 25.3 & $106.0 / 29.9$ & RAA & Renal insufficiency & $0 / 0$ & $0 / 0$ & 2 & $\begin{array}{l}\text { AoDesc } \\
\text { AoDesc }\end{array}$ & $23 \mathrm{y}$ & $\begin{array}{r}\text { MAPCA-stent } \\
\text { implantation }\end{array}$ \\
\hline 4 & 4.1 & $13.5 / 13.5$ & & $\begin{array}{l}\text { Left kidney } \\
\text { agenesis, right kidney } \\
\text { dysplasia }\end{array}$ & $1 / 1$ & $\mathrm{H} / \mathrm{H}$ & & $?$ & $\begin{array}{l}2 \mathrm{mo} \\
3.7 \mathrm{y} \\
3.8 \mathrm{y} \\
3.8 \mathrm{y}\end{array}$ & $\begin{array}{c}\text { MPA-AoAsc } \\
\text { (end-to-side)/S } \\
\text { Aoasc-LPA shunt/S } \\
\text { RPA-stent implantation } \\
\text { LBTS/LTh }\end{array}$ \\
\hline 5 & 17.7 & $51.0 / 18.1$ & Arrhythmia & $\begin{array}{l}\text { Hepatic dysfunction } \\
\text { left kidney cyst }\end{array}$ & $0 / 1$ & $\mathrm{H} / \mathrm{H}$ & 2 & $\begin{array}{l}\text { AoDesc } \\
\text { AoDesc }\end{array}$ & $\begin{array}{l}1.3 \mathrm{y} \\
8.5 \mathrm{y}\end{array}$ & $\begin{array}{l}\text { RV-PA conduit/S } \\
\text { VSD, ASD closure, } \\
\text { new conduit, } \\
\text { MAPCA-ligation/S } \\
\text { New conduit/S }\end{array}$ \\
\hline 6 & 36.0 & $54.0 / 17.6$ & RAA & Phlebothrombosis & $0 / 1$ & $\mathrm{H} / \mathrm{H}$ & 1 & AoDesc & & 0 \\
\hline 7 & 45.3 & $55.0 / 20.2$ & $\begin{array}{l}\text { RAA } \\
\text { Endocarditis } \\
\text { Arrhythmia }\end{array}$ & $\begin{array}{l}\text { Hepatic dysfunction } \\
\text { renal insufficiency }\end{array}$ & $1 / 1$ & $\mathrm{H} / \mathrm{H}$ & 1 & AoDesc & & 0 \\
\hline 8 & 39.4 & $58.0 / 20.1$ & Arrhythmia & $\begin{array}{l}\text { Hepatic dysfunction } \\
\text { renal insufficiency }\end{array}$ & $0 / 0$ & $0 / \mathrm{H}$ & 4 & $\begin{array}{l}\text { AoArch } \\
\text { AoDesc } \\
\text { AoDesc } \\
\text { AoDesc }\end{array}$ & $6.5 \mathrm{y}$ & Waterstone/RTh \\
\hline 9 & 45.6 & $58.0 / 20.1$ & $\begin{array}{l}\text { SV (RV), Hx, Dx, } \\
\text { CAVC, LCVS, situs } \\
\text { inversus atrialis; } \\
\text { arrhythmia }\end{array}$ & Renal insufficiency & $0 / 0$ & $0 / 0$ & 4 & $\begin{array}{l}\text { RSCA } \\
\text { AoArch } \\
\text { AoDesc } \\
\text { AoDesc }\end{array}$ & & 0 \\
\hline
\end{tabular}

MAPCA, Major aortopulmonary collateral artery; $B M I$, body mass index; $M P A$, main pulmonary artery; Confl, pulmonary arteries confluence; $L P A$, left pulmonary artery; $R P A$, right pulmonary artery; AoArch, aortic arch; $H$, hypoplastic; $\operatorname{Tr} B r$-ceph, truncus brachiocephalicus; LBTS, left Blalock-Taussig shunt; $L T h$, left posterolateral thoracotomy; $S$, sternotomy; $R A A$, right aortic arch; AoDesc, descending aorta; $A o A s c$, ascending aorta; $R V-P A$, right ventricle-pulmonary artery; $V S D$, ventricular septal defect; $A S D$, atrial septal defect; $R T h$, right posterolateral thoracotomy; $S V$, single ventricle; $R V$, right ventricle; $H x$, heterotaxy syndrome; $D x$, dextrocardia; $C A V C$, complete atrioventricular canal; $L S V C$, left superior vena cava; $R S C A$, right subclavian artery.

The patients with previous operations $(\mathrm{n}=4)$ were younger at the time of HLTx (median, 12.9 years; range, 4.1-39.4 years) than patients with no history of thoracic surgery (median, 35.9 years; range, 25.3-45.6 years), but the difference did not reach statistical significance $(P=.086)$.

During the HLTx, the median CPB time was 350 minutes (range, 199-625 minutes), and the median duration of aortic crossclamping was 198.5 minutes (range, 151-321 minutes).

Follow-up ranged between 2 days and 12.6 years (median, 1.2 years). The immediate postoperative course was complicated in $8(88.9 \%)$ patients by excessive bleeding, which required rethoracotomy within the first 24 hours. In $6(75 \%)$ of them, the re-exploration caused by bleeding was done more than once, and in $3(37.5 \%)$ patients it was done more than twice. In all cases bleeding was proved to be from the collateral vessels in the posterior mediastinum or in the chest wall. In the early postoperative period, these 8 patients required massive blood transfusions and received 8 to 43 packed red blood cell units (median, 24.5 units). Apart from bleeding, the most common postoperative complication was respiratory failure requiring prolonged mechanical ventilation (defined as assisted ventilation for $>72$ hours or reintubation), which occurred in $6(85.7 \%$ ) early survivors (Table 2$)$. The median ventilatory support time was 36 days (range, 18-77 days). Five (55.6\%) patients required tracheostomy. Acute renal failure (which required dialysis), was noticed in $5(55.6 \%)$ patients. The median length of intensive care unit stay among survivors was 58 days (range, 22-82 days), and the median length of hospital stay was 83 days (range, 35-136 days). Six early survivors among the transplant recipients were discharged from the hospital (1 patient is still in the intensive care unit). The most common late complication was bronchiolitis obliterans in $2(28.6 \%)$ patients, chronic renal failure in $2(28.6 \%)$ patients, and polyneuropathy in $2(28.6 \%)$ patients. All survivors after discharge were in New York Heart Association class I or II. 
TABLE 2. Complications and causes of deaths

\begin{tabular}{ll}
\hline & No. $(\%)$ \\
\hline In-hospital complications & \\
Early deaths & $2(22.2)$ \\
$\quad$ Case 5—graft dysfunction (myocardial infarction) & \\
$\quad$ Case 7—-multiorgan failure & \\
Early morbidity among early survivors & \\
$\quad$ Prolonged mechanical ventilation (>72 h) & $6(85.7)$ \\
Acute renal insufficiency & $5(71.4)$ \\
Infection, pulmonary & \\
Candida species & $4(57.1)$ \\
Aspergillus species & $2(28.6)$ \\
Cytomegalovirus & $1(14.3)$ \\
Infection, generalized & $2(28.6)$ \\
Lung acute rejection & $3(42.9)$ \\
Tracheal stenosis (stent implantation) & $1(14.3)$ \\
V. jugularis interna thrombosis (stent implantation) & $1(14.3)$ \\
Phrenic nerve injury & $1(14.3)$ \\
Late complications & $3(42.9)$ \\
Late deaths & \\
Case 1—pulmonary infection/bronchiolitis obliterans & \\
Case 2-bronchiolitis obliterans & \\
Case 3—renal insufficiency & $2(28.6)$ \\
Late morbidity among early survivors & $1(14.3)$ \\
Bronchiolitis obliterans & \\
Chronic renal insufficiency & \\
Polyneuropathy & \\
Tracheal stenosis (stent implantation) & \\
Aorta ascendens aneurysm & \\
\hline &
\end{tabular}

The hospital mortality rate was $22.2 \%(\mathrm{n}=2)$. In the late postoperative period, 3 patients died. The Kaplan-Meier survival curve of the entire group is presented on Figure 2. Early and late morbidity, as well as causes for early and late mortality, are shown in Table 2.

\section{DISCUSSION}

PA+VSD embryologically and anatomically is an extreme form of tetralogy of Fallot. This anomaly presents in a wide spectrum of severity according to the development of pulmonary arteries and occurrence of aortopulmonary collateral vessels.

The natural history of patients with PA+VSD is very poor. The probability of survival to the first birthday is only $60 \%{ }^{3}$ The most mild anatomic form (normally developed branch pulmonary arteries with duct-dependent pulmonary flow without MAPCAs) manifests very early, with profound cyanosis when the ductus closes. The children with the most severe anatomic form (absent main and branch pulmonary arteries with MAPCA-dependent pulmonary flow without ductus arteriosus) are usually free of symptoms for a long time. Ten percent of children might have the first diagnosis after the 10th year of life and maintain an excellent functional status into their teenage years or young adulthood. ${ }^{3}$

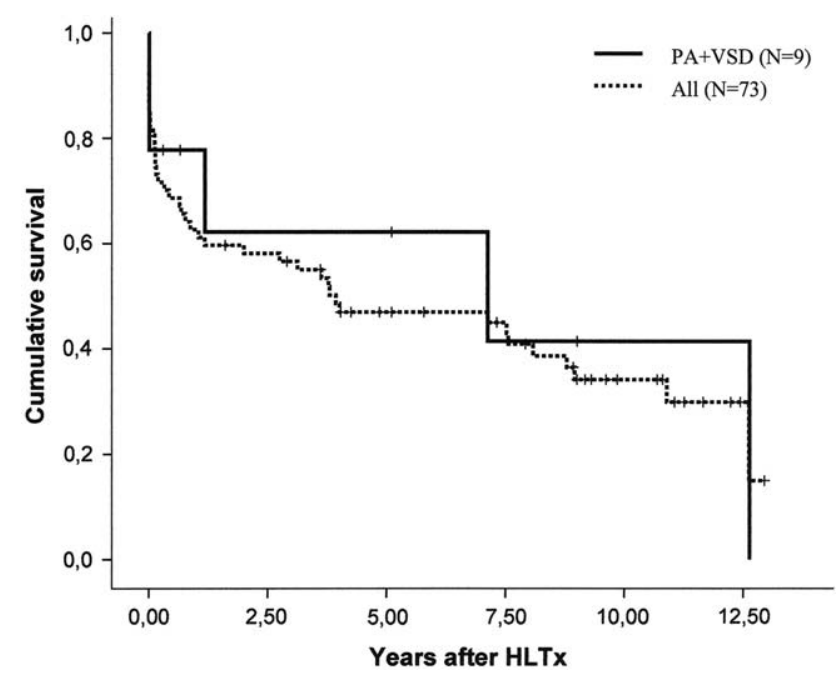

FIGURE 2. Actuarial survival after heart-lung transplantation (HLTx) in patients with pulmonary atresia and ventricular septal defect $(P A+V S D)$ in comparison with the whole group of HLTx recipients in our institution (All).

The gradual deterioration of oxygen saturation and reduction of effort tolerance are characteristic for adult cyanotic patients. ${ }^{4-6}$

Although pediatric cardiac surgery evolved significantly during the past decades, the strategy of surgical treatment for PA+VSD remains controversial. Definitive correction in early infancy can be applied without controversy in duct-dependent forms of the anomaly. ${ }^{711}$ In more severe anatomic forms, most authors advocate multistage repair. ${ }^{12-14}$ The association between the right ventricle and pulmonary circulation should be established as early as possible to ensure more normal development of alveolar number and the total cross-sectional area of pulmonary capillaries. ${ }^{10,12,13,15}$ Younger children ( $<5$ years of age) have the potential for development of the pulmonary tree. ${ }^{12}$ Older children, teenagers, or adult patients with PA+VSD have fewer generations of bronchoalveolar and pulmonary vascular tree, ${ }^{15}$ and surgical treatment in such patients is not only challenging, but also, the results are worse than the natural history of the disease. ${ }^{12,14}$ The only treatment option that can improve the prognosis for these patients is HLTx.

Palliative shunt procedures in children with PA+VSD are today more and more rarely performed. Dissection and suture lines are well-known causes of stenosis and distortion of the pulmonary arteries, impairing their future development. MAPCAs, which are muscular arteries until they penetrate the lung parenchyma (where they have an elastic media, like pulmonary arteries), have the tendency to develop severe stenoses. ${ }^{12}$ The junction between muscular and elastic segments (especially adjacent to bifurcation) is usually marked by an intimal hyperplasia that also partially obstructs the vessel. Beyond this stenosis, the vessel usually shows a sinusoidal dilation. ${ }^{15}$ The natural stenoses of 
collateral vessels protect the pulmonary circulation from the rapid development of obstructive disease. The surgically created systemic-to-pulmonary artery shunts do not have these protective changes and usually cause earlier development of histologic changes in the pulmonary vessels. ${ }^{15}$ Among our patients, we observed the tendency to be younger at the time of HLTx if the patient had undergone previous shunt procedures. We advocate that in patients with $\mathrm{PA}+\mathrm{VSD}$, the shunt procedures (as the only and long-term palliation) should be abandoned because they might worsen the natural history of the anomaly. If the specific anatomy is uncorrectable in early periods of life, multiple palliative procedures should be avoided because they not only do not improve the prognosis for the patient ${ }^{3}$ but also increase the risk of bleeding complications at HLTx. ${ }^{16}$

The most frequent postoperative complication in our patients was bleeding, which required re-exploration. Dense adhesions after previous operations, longstanding cyanosis, hepatic dysfunction, routine prophylactic preoperative anticoagulation, long CPB time, and massive transfusion are all factors that can contribute to bleeding complications. The previous history of thoracic surgery is a well-known risk factor for hospital death after HLTx ${ }^{17}$ and is even considered as a relative contraindication for HLTx by some authors. ${ }^{18}$ Adhesions caused by previous operations are associated with the presence of small vessels from the chest wall and usually are successfully controlled through the bilateral clamshell thoracotomy. ${ }^{19}$ In our opinion the bleeding complications are first of all associated with ineffective control of the true collateral vessels (MAPCAs). Meticulous hemostasis requires a precise preoperative definition of their origin, course, size, and number. It is crucially important for the surgeon to know the specific patient's anatomy before the operation and understand the relationship of the collateral vessels to other mediastinal structures.

MAPCAs embryologically are the persistence of connections between the aorta and the pulmonary vasculature. ${ }^{12,20}$ MAPCAs most commonly arise from the proximal descending aorta at the level of the tracheal carina (T4). Almost all arise 1 or 2 vertebral spaces above or below this level. ${ }^{12}$ About $55 \%$ patients with PA+VSD have more than 2 MAPCAs. ${ }^{3}$ Nevertheless, collateral vessels are highly variable in their size, number, course, origin, and arborization, and all available diagnostic methods should be used and carefully studied before embarking on the procedure.

The ligation or at least identification of collateral vessels should be performed, if possible, before the establishment of CPB. This strategy can not only shorten the CPB time, which per se is a risk factor for the postoperative bleeding, but also diminish the runoff through the collateral arteries to the pulmonary circulation and the danger of longstanding systemic hypoperfusion. Unfortunately, the majority of collateral vessels arise in the subcarinal region and require $\mathrm{CPB}$ to be reached. The use of moderate or deep hypothermia can help to dry the operative field through the opportunity of flow decreasing in the cardiopulmonary circulation. Apart from this measure, we also applied a maneuver of clamping the whole lung hilum or temporarily closing the pulmonary veins (tourniquets) to decrease the bleeding and approach the collaterals. The problem of collateral vessel control can be addressed by use of double aortic cannulation (ascending aorta and distal descending aorta) and exclusion of the proximal descending aorta from perfusion during hemostasis. ${ }^{21}$ Nowadays some of the large and difficult to reach MAPCAs can be controlled by using transcatheter techniques at the beginning of the HLTx (hybrid procedure). Perfect hemostasis is necessary to achieve before graft implantation because the region of bleeding is inaccessible at later time points. The proper time coordination between the donor and recipient team has a very important role in this specific group of patients. Sometimes meticulous hemostasis requires a lot of time, and the donor team should even wait for the recipient team to decrease the graft ischemic time to a minimum. The long graft ischemic time is a well-known cause of early graft failure, which is the most important reason for 30-day mortality after HLTx. ${ }^{1}$

Our results are encouraging because all survivors benefited from HLTx, both in terms of survival and quality of life. The overall mortality rate observed in the study series is comparable with that of the patients with other indications for HLTx operated on in our institution ${ }^{22}$ and with that noted by others. ${ }^{1,23}$ The results of our study indicate that HLTx in patients with PA+VSD requires carefully planned and meticulously performed surgical intervention. Nowadays HLTx is an established method of treatment for patients with end-stage cardiopulmonary disease. This management should be taken into consideration as a future option for children with $\mathrm{PA}+\mathrm{VSD}$ if the specific anatomy is uncorrectable in early periods of life. The multiple palliative procedures should be then avoided because they can worsen prognosis for the patient.

\section{References}

1. Trulock EP, Edwards LB, Taylor DO, Boucek MM, Mohacsi PJ, Keck BM, et al. The registry of the International Society for Heart and Lung Transplantation: twentieth official adult lung and heart-lung transplant report-2003. J Heart Lung Transplant. 2003;22:625-35.

2. Reitz BA, Wallwork JL, Hunt SA, Pennock JL, Billingham ME, Oyer PE, et al. Heart-lung transplantation: successful therapy for patients with pulmonary vascular disease. $N$ Engl J Med. 1982;306:557-64.

3. Bull K, Somerville J, Ty E, Spiegelhalter D. Presentation and attrition in complex pulmonary atresia. J Am Coll Cardiol. 1995;25:491-9.

4. Daliento L, Somerville J, Presbitero P, Menti L, Brach-Prever S, Rizzoli G, et al. Eisenmenger syndrome. Factors relating to deterioration and death. Eur Heart J. 1998; 19:1845-55.

5. Marelli AJ, Perloff JK, Child JS, Laks H. Pulmonary atresia with ventricular septal defect in adults. Circulation. 1994;89:243-51.

6. Wood P. The Eisenmenger syndrome or pulmonary hypertension with reversed central shunt. BMJ. 1958;27:755-62.

7. Reddy VM, Liddicoat JR, McElhinney DB, Brook MM, Stanger P, Hanley FL. Routine primary repair of tetralogy of Fallot in neonates and infants less than three months of age. Ann Thorac Surg. 1995;60(suppl 6):S592-6.

8. Pigula FA, Khalil PN, Mayer JE, del Nido PJ, Jonas RA. Repair of tetralogy of Fallot in neonates and young infants. Circulation. 1999;100(suppl II):II157-61. 
9. Di Donato RM, Jonas RA, Lang P, Rome JJ, Mayer JE Jr, Castaneda AR. Neonatal repair of tetralogy of Fallot with and without pulmonary atresia. $J$ Thorac Cardiovasc Surg. 1991;101:126-37.

10. Lofland GK. The management of pulmonary atresia, ventricular septal defect, and multiple aorta pulmonary collateral arteries by definitive single stage repair in early infancy. Eur J Cardiothorac Surg. 2000;18:480-6.

11. Abella RF, De La Torre T, Mastropietro G, Morici N, Cipriani A, Marcelletti C. Primary repair of pulmonary atresia with ventricular septal defect and major aortopulmonary collaterals: a useful approach. J Thorac Cardiovasc Surg. 2004;127: 193-202.

12. Jonas R. Tetralogy of Fallot with pulmonary atresia. In: Jonas R, ed. Comprehensive surgical management of congenital heart disease. 1st ed. London: Arnold; 2004. p. 440-56.

13. Gupta A, Odim J, Levi D, Chang RK, Laks H. Staged repair of pulmonary atresia with ventricular septal defect and major aortopulmonary collateral arteries: experience with 104 patients. J Thorac Cardiovasc Surg. 2003;126:1746-52.

14. Cho JM, Puga FJ, Danielson GK, Dearani JA, Mair DD, Hagler DJ, et al. Early and long-term results of the surgical treatment of tetralogy of Fallot with pulmonary atresia, with or without major aortopulmonary collateral arteries. $J$ Thorac Cardiovasc Surg. 2002;124:70-81.

15. Rabinovitch M, Herrera-deLeon V, Castaneda AR, Reid L. Growth and development of the pulmonary vascular bed in patients with tetralogy of Fallot with or without pulmonary atresia. Circulation. 1981;64:1234-49.
16. Reichenspurner H, Netz H, Uberfuhr P, Wagner FM, Vetter HO, Reichart B Heart-lung transplantation in a patient with pulmonary atresia and ventricular septal defect. Ann Thorac Surg. 1994;57:210-2.

17. Stoica SC, McNeil KD, Perreas K, Sharples LD, Satchithananda DK, Tsui SS et al. Heart-lung transplantation for Eisenmenger syndrome: early and longterm results. Ann Thorac Surg. 2001;72:1887-91.

18. Sheikh AY, Pelletier MP, Robbins RC. Heart-Lung and Lung Transplantation. In: Cohn LH, ed. Cardiac surgery in the adult. Part VIII: Transplant and circulatory support. 3rd ed. New York: McGraw-Hill Companies; 2007. p. 1579-608.

19. Luciani GB, Starnes VA. The clamshell approach for the surgical treatment of complex cardiopulmonary pathology in infants and children. Eur J Cardiothorac Surg. 1997;11:298-306.

20. McGoon DC, Baird DK, Davis GD. Surgical management of large bronchial collateral arteries with pulmonary stenosis or atresia. Circulation. 1975;52:109-18.

21. Kallenbach K, Simon AR, Haverich A, Struber M. Heart-lung transplantation in a patient with large aortopulmonary collaterals by means of an extended approach. J Thorac Cardiovasc Surg. 2007;134:543-4.

22. Reichart B, Gulbins H, Meiser BM, Kur F, Briegel J, Reichenspurner H. Improved results after heart-lung transplantation: a 17-year experience. Transplantation. 2003;75:127-32

23. Sarris GE, Smith JA, Shumway NE, Stinson EB, Oyer PE, Robbins RC, et al. Long-term results of combined heart-lung transplantation: the Stanford experience. J Heart Lung Transplant. 1994;13:940-9. 